compete for an enzyme with a substrate which it resembles in ring structure. The possibility that ascorbic acid may compete with hexose diphosphate for other enzymes such as aldolase or with other furanose-sugar phosphates, and thereby influence the course of carbohydrate or nucleotide metabolism, seems to us to be worthy of further investigation.

E. O'F. WALSH G. WALSH

Department of Physiology,

Royal Free Hospital School of Medicine, University of London. March 8.

${ }^{1}$ Gomori, G., J. Biol. Chem., 148, 139 (1943).

'Gulland, J. M., and Jackson, E. M., Biochem. J., 32, 590 (1938).

${ }^{3}$ Geiger, W. B., and Conn, J. E., J. Amer. Chem. Soc., 67, 112 (1945). Wallenfels, K., Chemie, 51, 1 (1945).

‘ Gould, B. S., J. Biol. Chem., 156, 365 (1944).

${ }^{5}$ Barron, E. S. G., and Singer, T. P., J. Biol. Chem., 157, 232 (1945).

'Hanes, C. S., Biochem. J., 29, 2588 (1935).

'Giri, K. V., Nature, 141, 119 (1938); Biochem. J., 33, 309 (1939).

\section{Influence of Folliculin on Bone Metabolism, Studied by Means of Radiophosphorus, ${ }_{15}^{32} \mathrm{P}$}

IN these experiments, all pigeons received daily $0.15 \mathrm{mgm}$. phosphorus labelled with radiophosphorus (subcutaneously) and $80 \mathrm{mgm}$. phosphorus provided by a normal diet (principally Indian corn). In addition, all pigeons, except control birds, received daily $0.25 \mathrm{mgm}$. aestradiol dipropionate ('Ovocycline P' Ciba, intramuscularly). The radiophosphorus was prepared by irradiations of phosphorus with deuterons produced by the cyclotron of the Laboratoire de Chimie Nucléaire of Paris (Prof. F. Joliot-Curie).
Humerus

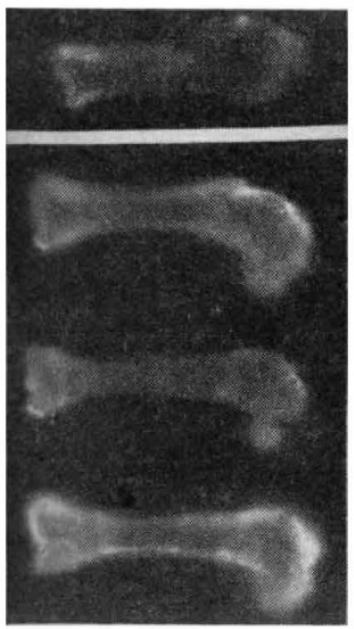

UPPER PHOTOGRAPHS : CONTROLS

LOWER THREE PHOTOGRAPHS : RFFECT OF FOLEIOULIN
The right-hand autoradiograph was taken after a 20-day treatment; it shows the femur of a control pigeon and those of three pigeons submitted to folliculin administration. The new medullary bone is very rich in injected radiophosphorus; the quantity of the latter present in the control femoral diaphysis, however, is clearly perceptible. It appears, indeed, according to the determination of radioactivity by means of a Geiger-Müller counter, that the new medullary bone contains on an average seven or eight times more injected radiophosphorus than the femur of a control pigeon. As it can be seen from the left-hand autoradiograph, the mineral metabolism of bones such as the humerus, the medullary cavities of which are not filled with folliculinic bone, is, however, accelerated under the influence of ostradiol; radiophosphorus takes the place of phosphorus in the diaphysis as well as in the epiphysis to a greater extent in the treated pigeon than in untreated ones.

By calculating the amount of ordinary phosphorus from food and of phosphorus from parenteral administration (radiophosphorus), by measuring the rate of elimination of both forms of phosphorus and the quantity of these two elements present in bone, we have found that nearly half the phosphorus present in new medullary bone does not come directly from phosphorus fed or injected, but from phosphorus already stored in the skeleton. The proportion of labelled phosphorus observed at the end of a 20-day experiment shows that nearly $13 \cdot 1$ per cent of bone phosphorus (femur) has been renewed in a pigeon receiving folliculin, but only $l \cdot 7$ per cent in the controls.

\section{J. Govakrts}

M. J. Dallemagne

Laboratory of Nuclear Physics and

Laboratory of Biochemistry, University of Liège.

Feb. 20.

\section{Sublittoral Seaweed Survey : Relationship of Algal Growth and Depth}

DURING the current survey of seaweed of the sublittoral zone of Scotland, very extensive sampling has been carried out. The samples are taken by means of a calibrated spring grab which closes by trigger action on touching bottom. The seaweed samples are weighed, species noted and also the depths from which they are obtained.

A survey of the sublittoral zone around the Argyll. shire coast ${ }^{1}$ has shown that a straight-line relationship exists between the mean density $\left(d_{t}\right)$ of the total number of sampling operations and the depth :

$$
d_{t}=5 \cdot 48-0 \cdot 34 f \text {, }
$$

where $d_{t}$ is density (kgm. $/ \mathrm{m.}^{2}$ ) and $f$ is depth (metres).

Laminaria Cloustoni is the dominant species. No large brown algæe were found below nine fathoms.

With the data obtained from the survey of Argyll. shire, it was estimated that more than one million tons of seaweed was likely to be found growing in Orkney waters. Surveys to date indicate this figure to be conservative.

The results of surveys in Scapa Flow, Orkney (800 acres), have again shown that a straight-line relationship occurs between mean density and depth :

$$
d_{t}=6.95-0.41 f \text {. }
$$

Laminaria Cloustoni is the dominant species, and the density of seaweed growth is greater than on the coast of Argyll. No very strong tidal streams occur in either of these two above areas.

Two separate and extensive surveys have been carried out on opposite sides of Wide Firth, Orkney, namely, the Bay of Firth (1,500 acres) and around 